\title{
A Social Work Model of Empathy
}

\author{
Karen E. Gerdes \\ Elizabeth A. Segal
}

\begin{abstract}
This article presents a social work model of empathy that reflects the latest interdisciplinary research findings on empathy. The model reflects the social work commitment to social justice. The three model components are: 1) the affective response to another's emotions and actions; 2) the cognitive processing of one's affective response and the other person's perspective; and 3) the conscious decision-making to take empathic action. Mirrored affective responses are involuntary, while cognitive processing and conscious decision-making are voluntary. The affective component requires healthy, neural pathways to function appropriately and accurately. The cognitive aspects of perspective-taking, self-awareness, and emotion regulation can be practiced and cultivated, particularly through the use of mindfulness techniques. Empathic action requires that we move beyond affective responses and cognitive processing toward utilizing social work values and knowledge to inform our actions. By introducing the proposed model of empathy, we hope it will serve as a catalyst for discussion and future research and development of the model.
\end{abstract}

Key Words: Empathy, social empathy, social cognitive neuroscience

\section{INTRODUCTION}

Ask a social worker if empathy is important to practice, and the response is likely to be "yes." Ask for a social work definition or social work conceptual model of empathy, and the response is likely to be "is there one?" Other disciplines have attempted to define empathy and construct models to explain what it is. Today, even politicians are weighing in on the importance of empathy. President Obama used "empathy" as one of his criteria for selecting a nominee to the Supreme Court (Hook \& Parsons, 2009). An examination of the emerging interdisciplinary research and literature on empathy, together with the strength of empathy as a tool for our professional work, make it imperative that social work embrace a model of empathy that not only fits but enhances our discipline. While other disciplines have their unique perspectives, their conceptualizations of empathy are not always a perfect fit for social work. In this article, we propose a social work model of empathy that reflects the latest interdisciplinary findings, particularly those of social cognitive neuroscience, and places them within the context of social work values and perspectives.

\section{Empathy is Critical to Social Work Practice - However it is Defined}

The list of studies in social work mentioning the importance of empathy is significant. Recent studies on the importance of practitioner-to-client empathy would fill several volumes. [Examples include Berg, Raminani, Greer, Harwood \& Safren (2008);

Karen E. Gerdes, Ph.D., is an associate professor and Elizabeth A. Segal, Ph.D., is a professor, both in the School of Social Work at Arizona State University.

Copyright (C) 2009 Advances in Social Work Vol. 10 No. 2 (Fall 2009), 114-127 
Forrester, Kershaw, Moss \& Hughes (2007); Green \& Christensen (2006); Mishara et al. (2007); and Sale, Bellamy, Springer \& Wang (2008)]. While empathy is essential to an effective client-worker relationship, it is also crucial that we help populations such as atrisk parents, partners, and sex offenders to develop and cultivate empathy (Curtner-Smith et al., 2006, Busby \& Gardner, 2008; Hunter, Figueredo, Becker \& Malamuth, 2007; Waldinger, Schultz, Hauser, Allen \& Crowell 2004). Parental empathy has been cited as crucial for raising healthy children (Curtner-Smith et al., 2006). Partner empathy is a key element in satisfying relationships (Busby \& Gardner, 2008; Waldinger et al., 2004). Empathy is one of the core elements of healthy relationships at every level, and is therefore a pivotal theme in social work theory and practice.

Interestingly though, empathy is never mentioned in the NASW Code of Ethics nor does it have an entry in the Encyclopedia of Social Work. Empathy is listed once in the CSWE Educational Policy and Accreditation Standards [Section 2.1.10(a)] (Council on Social Work Education, 2008) as one of several general components of practice. The Social Work Dictionary (Barker, 2003) does provide an entry and defines empathy broadly as "The act of perceiving, understanding, experiencing, and responding to the emotional state and ideas of another person" (p. 141). The ubiquitous nature of empathy in social work practice and the lack of a concrete conceptualization of empathy, rather than a lack of regard for the importance of empathy may explain its limited presence in important social work documents.

The very familiarity of the word "empathy" renders it somewhat vague. Common usage often creates false assumptions and misunderstandings, and this process is definitely at work in current social work literature on empathy. Morgan and Morgan (2005) noted that most social work researchers and educators seem to assume simply telling practitioners "Empathy is very important" is enough to convey a precise message and make the listeners proficient in practice - an assumption which, however wellintentioned, is incorrect. Pithers (1999) noted that "operational definitions [of empathy] are not consistent across studies" (p. 258) and there has been considerable confusion over whether empathy is a multidimensional or unidimensional construct. As a result of this semantic fuzziness, conceptualizations and measurement techniques for empathy vary so much that it has been difficult to engage in meaningful comparisons or make significant conclusions about how we define empathy, measure it, and effectively cultivate it in social workers and clients (Cliffordson, 2001). Lest we are overly critical of social work, these problems of definition, measurement and conceptualizations are shared across disciplines, and likely have contributed to social work's lack of depth in both how we define and how we teach empathy.

There is a general agreement across disciplines that empathy is the ability to imagine what another person is feeling and thinking. In this context, empathy has been presented as a dispositional trait, a cognitive skill, a physiological reaction or some combination of these components. Is it an innate trait? A cognitive skill? Is it a feeling, a thought, or an action? Can it be taught? Can it be learned? If we have it, can we develop more? To develop, cultivate, and use empathy effectively in practice, it would be beneficial to have a model that answers these questions, and we propose such a model. 


\section{WHAT DO WE KNOW (ALMOST) FOR SURE ABOUT EMPATHY?}

\section{Empathy and Developmental Psychology}

German and American psychologists, Theodor Lipps (1903) and Edward Tichener (1909) first used the word "einfühlung" or "empathy" to describe a psychological phenomenon or the inner imitation an observer experiences when observing another person or object (Davis, 1996; Iacoboni, 2008). Empathy was conceived as both a passive reflection of another, and as an active effort to get inside another. The dual nature of empathy, while not initially embraced by every researcher across disciplines, is now widely acknowledged. Hoffman (1984) and other developmental psychologists placed empathy and its dual nature in the context of the continuum of human development.

Developmental psychologists recognized that as infants we rely on mimicry to develop our ability to automatically recognize what our parents and others are feeling. As we age, we develop the ability to take on other roles and imagine the feelings of others (i.e., the cognitive processing part of empathy). More recently, Hoffman (2000) put forth five modes of empathic arousal. The first three are automatic, involuntary and hence primitive: mimicry, conditioning, and direct association. The other two, which are culturally influenced and involve cognition, are mediated association and role-taking. Hoffman's focus was on "empathic distress" because he regarded the discomfort of seeing someone in distress as what motivates people to prosocial moral action.

Alleviation of distress was part of the motivation behind psychological research on empathy during the early 1990s. Batson (1991) viewed empathy as a means to altruistic behavior. He and his co-researchers argued that empathy is related to other personal motives, such as reducing the pain of watching and feeling others suffer or for the sense of rewards in helping others (Batson et al., 1991). His link to altruism is persuasive, but not conclusive. The research used stories of personal distress, and asked participants whether they would help. Such experiments were all hypothetical and did not measure mirroring or physiological affective responses. Thus, "empathy" may lead to altruistic outcomes, but it also may not. People may "do good deeds" for all sorts of reasons, including personal reward or satisfaction, sympathy, guilt, or due to other egoistic motivations. The contributions of Batson's research to analyzing the link between empathy and positive social outcomes is an important part of our understanding of empathy. But the confirmation of the physiological imperative of empathy had yet to be discovered.

Davis (1996) developed a model that includes most of the empathy constructs that have been developed prior to the recent neurobiological discoveries related to empathy. His model starts with what he calls antecedents, goes through multiple processes, and results in outcomes. The antecedents include biological capacities as well as learned socializations. The processes include the action of motor mimicry as well as active cognitive processing. The outcomes are divided into two categories, intrapersonal and interpersonal, including affective response (physiologically feeling something), and cognitive processing of attribution (figuring out how the other person feels and why based on the observed behaviors). His model, while comprehensive and inclusive of all 
major concepts, is very complicated and mixes the physiological and cognitive aspects of empathy throughout the model. He does include the outcomes of empathic feelings, but limited to the individual level.

\section{Empathy and Mirror Neurons}

In recent years, a great deal of research in the field of social cognitive neuroscience has emerged identifying the biophysical components that mediate empathy in the brain (Decety \& Jackson, 2004; Decety \& Lamm, 2006; Decety \& Moriguchi, 2007). This new neuroscience uses sophisticated brain imaging equipment to confirm what many have suspected for years: that when we see another person's actions (for example pain, laughing or crying), our bodies respond as if we feel a degree of that action too. This phenomenon is called mirroring, and the circuitry of the brain responsible for this are called mirror neurons (Iacoboni, 2008). These cells that transmit nerve impulses are defined as "neurons that fire when an action is performed or when the same action is observed" (Kaplan \& Iacoboni, 2006, p. 175). This may seem simple, but the confirmation is significant.

We now know through the work of neuroscientists that the human brain is wired to mimic other people, and this mimicry involves actual involuntary, physiological experience in the observer. Human beings tend to imitate actions that they see. Physiologically, our brains include mirror neurons, which react to actions that are seen as if we are doing the action ourselves. It is largely an unconscious and automatic experience. When we hear people speak, observe their vocal nuances, watch their posture, gestures, and facial expressions, etc., neural networks in our brains are stimulated by the "shared representations," generating feelings within us that reflect the experience of those we are observing. "Our drive to imitate seems to be powerfully present at birth and never declines" (Iacoboni, 2008, p. 47). Imitation helps us to learn to interact with our surroundings and socialize. It may be a key component for learning to speak. Research suggests that the more imitation a toddler engages in, the better the child's later facility at speaking and language acquisition (Nadel, 2002; Eckerman \& Didow, 1996). The lack of physiological mirroring seems to relate to a lack of empathy. Neurologists have discovered some evidence that affective sharing is physically diminished in people with autism (Dapretto et al., 2006; Decety \& Moriguchi, 2007). Earlier research found that brain injury diminished empathy (Eslinger, 1998). These findings suggest that genetics or biological composition may play a role in human capacity to experience affective sharing. Iacoboni (2008) explains the entire neurological process as follows:

Mirror neuron areas help us understand the emotions of other people by some form of inner imitation. According to this mirror neuron hypothesis of empathy, our mirror neurons fire when we see others expressing their emotions, as if we were making those facial expressions ourselves. By means of this firing, the neurons also send signals to emotional brain centers in the limbic system to make us feel what other people feel (p. 119). 
While the response is automatic and hence involuntary, there is a conditioning element as well. From a young age children are often reinforced for their imitative behavior, particularly if those behaviors are socially desirable. For example, adults often smile at babies and try to get them to smile back. As the infant is hard-wired to imitate, it does smile back, delighting the adult, which gives the infant positive reinforcement for the mirroring.

\section{A SOCIAL COGNITIVE NEUROSCIENCE CONCEPTUALIZATION OF EMPATHY}

Decety and colleagues (Decety \& Jackson, 2004; Decety \& Lamm, 2006; Decety \& Moriguchi, 2007) combined cumulative, qualitative descriptions of empathy from the social sciences with the new findings in social cognitive neuroscience, which led to a conceptualization of empathy as the dynamic interaction of four "neural networks." All four networks are empirically observable brain phenomena, and all four components must come into play for a human to experience the full extent of empathy. If any of the components is missing or inhibited, the subjective experience of empathy fails to emerge. The components identified by Decety and colleagues are listed below (Decety \& Moriguchi, 2007, p. 4).

1. Affective sharing. The experience of similar emotions between the self and an other, "based on automatic perception-action coupling and shared representations." (See the previous discussion on mirror neurons).

2. Self awareness. "Even when there is some temporary identification between the observer and its target, there is no confusion between self and other."

3. Mental flexibility. The cognitive capacity to imagine another's situation "from the inside," "to adopt the subjective perspective of the other."

4. Emotion regulation. "The regulatory processes that modulate the subjective feelings associated with emotion.”

\section{Self-Awareness}

Self-awareness refers to recognizing and understanding one's own emotions, strengths, limitations, and motives (Goleman, Boyatzis \& McKee, 2002). London (2002) describes it as "self-insight" or the ability to be self-understanding, self-monitoring, and self-evaluating. Both these authors agree that healthy, high-functioning individuals are consistently aware of their own emotional condition, but are also conscious of how they impact others. In other words, high-functioning social beings are aware of both their private and public selves: what they perceive, and how they are perceived by others.

\section{Mental Flexibility/Perspective-taking}

Mental flexibility, also called perspective-taking, is mediated in a part of the brain that deals with executive function-a task-based way of getting things done. It is the ability to toggle between what you are feeling and what the other person is feeling, while maintaining the self-awareness to know there is a boundary between the two. Simply put, 
the brain treats mental flexibility as a job, not a feeling. It requires a logistical, rational understanding of other people's experience. For example, a parent may have to logically take the perspective of an infant to imagine what it would be like to be weak, small, helpless, preverbal, and so on. At the same time, the parent must be aware of his or her own perspective as the strong adult who can care for this weak, helpless infant. Mental flexibility is the understanding that the other person is like me, but is not me. Role taking is another component often considered part of empathy. While others have described it in terms of child development, Davis (1996) includes it in his discussion of empathy, citing it as a "cognitive process in which the individual suppresses his or her usual egocentric outlook and imagines how the world appears to others" (p. 6).

\section{Emotion Regulation}

Emotion regulation refers to an internal ability to change or control one's own emotional experience. Sometimes, feeling what others are feeling can be overwhelming, and one can lose sight of whose feelings are whose. We might see this as overidentification with another person, or from a clinical perspective see it as lack of boundaries. Most people use a variety of cognitive and affective strategies to achieve emotion regulation; soothing self-talk, motivational visualizations, seeking affirmation from others, listening to music, and so on. Psychotherapists and, of course, social workers are often responsible for teaching clients emotion regulation techniques (Linehan, 1993). One way that we may regulate our emotions is through judgment. To what extent we believe people "deserve" to feel the way they do can impact our empathy towards them (Davis, 1996). In fact, we may have a bias towards those we deem worthy of our concern. There is a tremendous amount of literature on group or kin selection, which is far beyond the scope of this article (see Hamilton, 1964; Hoffman, 1981). However, the tendency to favor survival and reproduction of those who share our genetic make-up in order to ensure the continuation of our species can affect our processing of empathic feelings. If we are taught that we are different from another tribe, or race, for example, then we can pass judgment that cognitively overrides empathic affective responses we may have. Such cognitive processing may be the reason people have been able to witness atrocities against other human beings and stifle, ignore or process away sharing of feelings. If the slave being whipped before your eyes is regarded as different from you or inhuman, then feelings of empathy can be cognitively dismissed. We conclude that the voluntary aspects of cognitive processing are part of our socialization and therefore can be taught.

While part of this interdisciplinary model is known territory for social work researchers, the neurological evidence supporting the model has powerful new implications. In recent years, neuroimaging studies have allowed scientists to locate the neural networks in specific parts of the brain that mediate each of the four components of empathy. Detailing all of the brain studies is beyond the scope of this article, but the work of Decety and colleagues (Decety \& Jackson, 2004; Decety \& Lamm, 2006; Decety and Moriguchi, 2007) provides evidence of this link.

These four components go far in linking earlier psychological research with recent neuroscience findings to conceptualize empathy. However, what is missing is a broader environmental component and the place of social justice. We propose building on this 
model and adding aspects that take into consideration environmental contexts and social justice.

\section{A SOCIAL WORK MODEL OF EMPATHY}

Based on the aforementioned theorists and numerous studies on empathy as an intellectual foundation, coupled with years of social work experience, we have developed a model that incorporates the findings of other disciplines, particularly social cognitive neuroscience, but is uniquely placed within social work. This model reflects the personin-environment approach of social work and the commitment to social justice, which is a core value of the profession (NASW, 2008). The model we propose consists of three components, all of which build upon the prior part: 1) the affective response to another's emotions and actions; 2) the cognitive processing of one's affective response as well as the other person's perspective; and 3) the conscious decision-making to take empathic action. Table 1 outlines the model.

Table 1: $\quad$ Social Work Model of Empathy

\begin{tabular}{|c|c|c|c|}
\hline Component & Definition & Key Aspects & Ways to Develop \\
\hline $\begin{array}{l}\text { Affective } \\
\text { Response }\end{array}$ & $\begin{array}{l}\text { Involuntary, physiological } \\
\text { reaction to another’s } \\
\text { emotions and actions. }\end{array}$ & $\begin{array}{l}\text { Mirroring }{ }^{1,2,3,4} \\
\text { Mimicry }^{5} \\
\text { Conditioning }^{6}\end{array}$ & $\begin{array}{l}\text { Promote healthy } \\
\text { neurological } \\
\text { pathways }\end{array}$ \\
\hline $\begin{array}{l}\text { Cognitive } \\
\text { Processing }\end{array}$ & $\begin{array}{l}\text { Voluntary mental thought } \\
\text { processes used to interpret } \\
\text { one's affective response; } \\
\text { enables one to take the } \\
\text { other person's perspective. }\end{array}$ & $\begin{array}{l}\text { Self- awareness } \\
{ }^{6} \\
\text { Mental flexibility }^{7} \\
\text { Role taking }^{6} \\
\text { Emotion regulation }^{7,8} \\
\text { Labelling }^{6} \\
\text { Judgment }^{6} \\
\text { Perspective taking }^{7,8} \\
\text { Self-agency }^{8}\end{array}$ & $\begin{array}{l}\text { Set boundaries } \\
\text { Practice } \\
\text { mindfulness } \\
\text { Use role plays }\end{array}$ \\
\hline $\begin{array}{l}\text { Conscious } \\
\text { Decision-making }\end{array}$ & $\begin{array}{l}\text { Voluntary choices for } \\
\text { action made in response to } \\
\text { cognitive processing. }\end{array}$ & $\begin{array}{l}\text { Empathic action }{ }^{9} \\
\text { Social empathy }^{10,11,12,13} \\
\text { Morality }^{5} \\
\text { Altruism }\end{array}$ & $\begin{array}{l}\text { Helping } \\
\text { Advocacy } \\
\text { Organizing } \\
\text { Social Action }\end{array}$ \\
\hline $\begin{array}{l}{ }^{1} \text { Iacoboni (2008) } \\
{ }^{2} \text { Kaplan \& Iacoboni } \\
{ }^{3} \text { Gallese \& Goldman } \\
{ }^{4} \text { Rizzolatti \& Craigh } \\
{ }^{5} \text { Hoffman (2000) } \\
{ }^{6} \text { Davis (1996) } \\
{ }^{7} \text { Decety \& Moriguch } \\
{ }^{8} \text { Decety \& Jackson ( }\end{array}$ & $\begin{array}{l}006) \\
1998) \\
o(2004)\end{array}$ & $\begin{array}{l}{ }^{9} \text { Gerdes \& Segal (In press) } \\
{ }^{10} \text { Segal (2008) } \\
{ }^{11} \text { Segal (2007a) } \\
{ }^{12} \text { Segal (2007b) } \\
{ }^{13} \text { Segal (2006) } \\
{ }^{14} \text { Batson (1991) } \\
{ }^{15} \text { Batson et al. (1991) } \\
{ }^{16} \text { Batson et al. (2003) }\end{array}$ & \\
\hline
\end{tabular}

The first component, affective response, encompasses the involuntary physical reactions we have that are triggered by our exposure to external events. The second component of empathy is the cognitive processing of mirrored emotions and actions. This 
process is voluntary mental thought that strives to interpret the physiological sensations as well as the thoughts that mirroring triggers. It includes the components of selfawareness, mental flexibility and emotion regulation. This process results in an understanding of the lived experiences of others. The third component, conscious decision-making is the piece that draws from social work, the need to take action. The imperative of social justice, which is clearly outlined as a value of social work (see the NASW Code of Ethics and the CSWE Educational Policy and Accreditation Standards, 2008) (Council on Social Work Education, 2008; National Association of Social Workers, 1999), requires that social workers engage in practices that advance social justice. To empathically understand people means to enter into their situations in ways that reveal inequalities and disparities. Such awareness must be followed by action to promote fairness, which is the advancement of social justice.

Our proposed model requires that all three components of empathy be present in order to experience empathy that is rooted in social justice as well as social cognitive neuroscience. It is currently not possible to weigh each component. However, the extent of mirroring, processing, and action-taking may vary in different circumstances. What neuroscience has proven through the use of brain imaging (fMRI) is that affective response must be followed by cognitive processing to experience empathy (Decety \& Moriguchi, 2007).

\section{Is Empathic Action a Necessary Component of Empathy?}

The first two components, affective response and cognitive processing, are widely accepted as the necessary components of empathy and typically discussions of empathy end after describing these components. As Decety \& Moriguchi (2007) identify in their list of components, empathy exists when there is affective sharing, self-awareness, mental flexibility and emotion regulation. In their model, taking action based on the affective response and cognitive processing is not required for one to experience the full extent of empathy. Davis' (1996) model is multi-dimensional and includes outcomes, but is limited to the individual. The author himself notes this as a limitation (p. 220). For Hoffman (2000) empathy "might transform the task of choosing among abstract principles into an empathy-relevant task that leads one to imagine the consequences of different systems for society's least advantaged people or for people who work hard (p. 230).” He hopes that empathy can be linked to caring and justice principles (p. 298). Iacoboni (2008) accepts that although we have neuroscientific evidence of empathy, it does not guarantee action. He hopes that "a more explicit level of understanding of our empathetic nature will at some point be a factor in the deliberate, reflective discourse that shapes society” (p. 271).

We argue that empathy is not simply a condition, a nature, or a domain, rather it is an induction process that culminates in empathic action. Empathic action is the result of the third component of the model, conscious decision-making. In our view, and more specifically from a social work perspective, having empathic feelings and participating in perspective-taking is not the full extent of empathy. Having empathy includes voluntarily taking action in response to the cognitive processing that is in response to the initial affective response. This is where social work's value of social justice and full integration of person-in-the-environment comes into play. As social workers, to be empathic is to 
experience the affect, process it, and then take appropriate, effective, empathy-driven action. The empathic actions we take can impact individuals, groups, communities and even society. Segal (2007a; 2007b; 2008) describes social empathy, which is the action of using our empathic experiences and understanding to shape public policy. This is a form of empathic action. Without action in response to the empathic induction process, we believe a person is not truly empathic. A social work model of empathy includes action. Being empathic means understanding the situation of others and taking action in response to the interpretation of the situation. Two examples illustrate the point.

\section{The Empathy Model in Action}

New social workers often find themselves overwhelmed the first time they visit a family in a socially and economically isolated neighborhood. The deprivation and desperation is often visible everywhere. For example: A family preservation worker visits a single mother living in a poor, rural area. The mother has been referred by her children's teacher who is afraid the children are being neglected. The mother appears depressed; she has no food to put on the table for dinner. If the worker does not have an advanced degree of self-awareness, and has not been trained to cognitively process his or her affective responses in this situation, it is easy to be overcome with feelings of pity and sympathy. There is an overwhelming urge to jump in and try to solve an immediate problem - for instance, to give the mother money to buy food for dinner or to go to the store and buy food for the family. An empathic action or response is to help the mother assess her situation, identify resources she can rely on in an emergency (e.g., family, neighbors, local food bank) and then help her to plan ways to avoid being in this situation again. Consideration of the larger environment as part of the worker's cognitive processing may also require action on a macro level, such as helping to create employment opportunities. Pity and sympathy often inspire actions that are enabling or disempowering, whereas empathic action is driven by knowledge of the person-inenvironment framework and the strengths perspective and result in empowerment.

There are several examples of social policies that have been, at least in part, the result of empathic action. For example, when Robert Kennedy visited Jackson, Mississippi in 1967, he introduced the country to a level of hunger and malnutrition that few were even aware existed in the United States. Kennedy's description of his visits with families were not only inspiring, they were filled with empathy. As a result, he was able to push Congress to open the Food Stamps Program and provide stamps for the needy (Mills, 2006). When decision-makers like Kennedy are able to toggle back and forth between what it would be like to live in a poor Mississippi community, and their own life experience, they are more readily able to identify social and economic inequities. On the other hand, staying away from personal visits and labeling people living in poverty as "undeserving" or "lazy" allows decision-makers to separate themselves from the people in need and thereby avoid issues of social justice. Empathy requires moving beyond feeling sympathy or pity and being overwhelmed by the seeming hopelessness of the situation. It is imperative that social workers be taught and trained to practice selfawareness, mental flexibility, emotion regulation, and perspective taking. Mental flexibility encourages us to ask what is fair and right; self-other awareness and emotion 
regulation can help prevent compassion fatigue and burnout. An empathic perspective is more likely to result in actions that utilize strengths, empower clients, and promote social and economic justice.

\section{Is Empathy All or Nothing?}

Our model includes both unconscious or automatic affective responses and cognitive processing as well as consciously choosing to take empathy-driven action. However, the extent to which we can experience all three components, or the full extent of empathy, when confronted by any given situation varies greatly. This suggests that there is a dynamic nature to empathy. Some aspects are experienced more than others, and in varying degrees by different people. This is due in part to varying skill levels required for effective cognitive processing as well as variation in the strength of healthy neural pathways.

The experience of empathy is not perfectly linear, although the model is described in a progressive, linear fashion. However, if we try to define empathy without including all three components, then we dilute the meaning and power of the concept. Empathy from a holistic social work perspective needs to include all three components. Empathy is not only a condition, it is an action motivated by affect and cognition.

One important caveat is in order. The involuntary act of mirroring is not discerning. Human beings are hard-wired to mimic, thus they can be as likely to mirror positive actions as well as negative actions. Iacoboni (2008) warns us that empathy in action is not always positive. He hypothesizes that we have atrocities because we have imitative violence, we can dissociate our mental processes from our reflexive behavior, and that cross-cultural opportunities for mirroring can be countered by the influence of massive religious and political belief systems that keep us apart and deny the neurobiology that links us together. So part of the social work challenge of our model is to not only link action to affect and cognition, but to nurture action that is positive, that promotes wellbeing, that is socially just. By building a framework of empathy on the principles of social justice, we can promote imitation of socially constructive behaviors and cognitive processing that stress our similarities rather than beliefs that are created to divide us.

\section{CONCLUSION}

Our mirrored affective responses are involuntary; cognitive processing and conscious decision-making are voluntary. The affective component requires healthy, lesion-free neural pathways to function appropriately and accurately. Empathy deficits have been linked to damaged and/or underdeveloped neural circuitry (Dapretto et al., 2005; Decety \& Moriguchi, 2007). However, we can help people create new neural pathways to improve their ability to effectively mirror another person's actions and emotions. The cognitive aspects of perspective-taking, self-awareness, and emotion regulation can be practiced and cultivated, particularly through the use of mindfulness techniques.

Empathic action requires that we move beyond affective responses and cognitive processing toward utilizing social work values and knowledge to inform our action choices. All three components of the model can be taught, practiced, and cultivated. By 
introducing the proposed model of empathy, we hope social work researchers will engage in a critical discussion of the model and begin research that can help validate the model. For example, what are the benchmarks for social workers in terms of empathy levels required to be an effective practitioner? We are currently field testing a scale that incorporates the three components of empathy. It is our hope that in the near future, by utilizing this model social work practitioners can better cultivate client-worker empathy, and teach clients how to develop greater empathy. Finally, we believe that the importance the social work profession has placed on empathy must be be matched with a conceptualization of empathy that is sophisticated and rich with implications for becoming more effective practitioners.

\section{References}

Barker, R. L. (2003). The social work dictionary. Washington, DC: NASW Press.

Batson, C. D. (1991). The altruism question: Toward a social-psychological answer. Hillsdale, NJ: Erlbaum.

Batson, C. D., Batson, J. G., Slindsby, J. K., Harrell, K. L., Peekna, H. M., \& Todd, M. (1991). Empathic joy and the empathy-altruism hypothesis. Journal of Personality and Social Psychology, 61(3), 413-426.

Batson, C. D., Lishner, D. A., Carpenter, A., Dulin, L., Harjusola-Webb, S., \& Stocks, E. (2003). “... as you would have them do unto you”: Does imagining yourself in the other's place stimulate moral action? Personality \& Social Psychology Bulletin, 29, 1190-1201.

Berg, D., Raminani, S., Greer, J., Harwood, M., \& Safren, S. (2008). Participants' perspectives on cognitive-behavioral therapy for adherence and depression in HIV. Psychotherapy Research, 18(3), 271-280.

Busby, D. M., \& Garnder, B. C., (2008). How do I analyze thee? Let me count the ways: Considering empathy in couple relationships using self and partner ratings. Family Process, 47(2), 229-242.

Cliffordson, C. (2001). Parents' judgments and students' self-judgments of empathy. European Journal of Psychological Assessment, 17(1), 36-47.

Council on Social Work Education. (2008). Educational policy and accreditation standards. Alexandria, VA: Author.

Curtner-Smith, M. E., Culp, A. M., Culp, R., Scheib, C., Owen, B. S., Tilley, A., Murphy, M., Parkman, L., \& Coleman, P. W. (2006). Mothers' parenting and young economically disadvantaged children's relational and overt bullying. Journal of Child and Family Studies, 15(2), 181-193.

Dapretto, M, Davies, M. S., Pfeifer, J. H., Scott, A. A., Sigman, M., Bookheimer, S. Y., \& Iacoboni, M. (2006). Understanding emotions in others: mirror neuron ysfunction in children with autism spectrum disorders. Nature Neuroscience, 9(1), 28-30. 
Davis, M. H. (1996). Empathy: A social psychological approach. Boulder, CO: Westview Press.

Decety, J., \& Jackson, P. L. (2004). The functional architecture of human empathy. Behavioral Cognitive Neuroscience Review, 3(2), 71-100.

Decety, J., \& Jackson, P. L. (2006). A social-neuroscience perspective on empathy. Current Directions in Psychological Science, 15(2), 54-58.

Decety, J., \& Lamm, C. (2006). Human empathy through the lens of social neuroscience. The ScientificWorldJournal, 6, 1146-1163.

Decety, J., \& Moriguchi, Y. (2007). The empathic brain and its dysfunction in psychiatric populations: Implications for intervention across different clinical conditions. BioPsychoSocial Medicine, 1, 22-43.

Eckerman, C. O., \& Didow, S. M. (1996) Nonverbal imitation and toddlers’ mastery of verbal means of achieving coordinated actions. Developmental Psychology, 32, 14152.

Eslinger, P. J. (1998). Neurological and neuropsychological bases of empathy. European Nerurology, 39, 193-199.

Forrester, D., Kershaw, S., Moss, H., \& Hughes, L. (2007). Communication skills in child protection: How do social workers talk to parents? Child and Family Social Work, 13, 41-51.

Gallese, V., \& Goldman, A. (1998). Mirror neurons and the simulation theory of mindreading. Trends in Cognitive Sciences, 2(12), 493-501.

Gerdes, K. E., \& Segal, E. A. (in press). The importance of empathy for social work practice: Integrating new science. Social Work.

Goleman, D., Boyatzis, R., \& McKee, A. (2002). Primal leadership: Realizing the power of emotional intelligence. Boston: Harvard Press.

Green, E. J., \& Christensen, T. M. (2006). Elementary school children's perceptions of play therapy in school settings. International Journal of Play Therapy, 15(1), 65-85.

Hamilton, W. D. (1964). The genetic evolution of social behavior. Journal of Theoretical Biology, 7, 1-52.

Hoffman, M. L. (1981). Is altruism part of human nature? Journal of Personality and Social Psychology, 40(1), 121-137.

Hoffman, M. L. (1984). Interaction of affect and cognition in empathy. In C. E. Izard, J. Kagan, \& R. B. Zajonc (Eds.), Emotions, cognition, and behavior (pp. 103-131). Cambridge: Cambridge University Press.

Hoffman, M. L. (2000). Empathy and moral development: Implications for caring and justice. New York: Cambridge University Press. 
Hook, J., \& Parsons, C. (2009, May 2). Obama says empathy key to court pick; As the president looks for Souter's successor, fellow Democrats split on whether to steer to the center or the left. The Los Angeles Times, National p. 1.

Hunter, J. A., Figueredo, A. J., Becker, J. V., \& Malamuth, N. (2007). Non-sexual delinquency in juvenile sex offenders: The mediating and moderating influences of emotional empathy. Journal of Family Violence, 22, 43-54.

Iacoboni, M. (2008). Mirroring people: The new science of how we connect with others. New York: Farrar, Straus and Giroux.

Kaplan, J. T., \& Iacoboni, M. (2006). Getting a grip on other minds: Mirror neurons, intention understanding, and cognitive empathy. Social Neuroscience, 1(3/4), 175183.

Linehan, M. M. (1993). Cognitive-behavioral treatment of borderline personality disorder. New York: Guilford Press.

Lipps, T. (1903). Einfühlung, inner Nachahmung, und Organaempfindaungen. Archiv für die gesamte psychologie, 1, 465-519. [Translated as "Empathy, inner imitation and Sense-Feelings” in M. M. Rader (Ed.), (1979), A modern book of esthetics ( $5^{\text {th }}$ ed., pp. 374-382). New York: Holt, Rinehart and Winston].

London, M. (2002). Leadership development: Paths to self-insight and professional growth. New York: Lawrence Erlbaum Associates.

Mills, N. (2006). Hurrican Katrina and Robert Kennedy. Dissent Magazine, 53(2): 5-6

Mishara, B. L., Chagnon, F., Daigle, M., Balan, B., Raymond, S., Marcoux, I., Bardon, C., Campbell, J. K., \& Berman, A. (2007). Which helper behaviors and intervention styles are related to better short-term outcomes in telephone crisis intervention? Results from a silent monitoring study of calls to the U.S. 1-800-SUICIDE network. Suicide and Life-threatening Behavior, 37(3), 308-321.

Morgan, W. D., \& Morgan, S. T. (2005). Cultivating attention and empathy. In C. K. Germer, R. D. Siegel, \& P. R. Fulton (Eds.), Mindfulness and psychotherapy (pp. 7990). New York: Guilford Press.

Nadel, J. (2002). Imitation and imitation recognition: Functional use in preverbal infants and nonverbal children with autism. In A. N. Meltzoff and W. Prinz (Eds.), The imitative mind: Development, evolution and brain bases (pp. 42-57). Cambridge, UK: Cambridge University Press.

National Association of Social Workers. (1999). NASW Code of Ethics. Washington, DC: Author.

Pithers, W. (1999). Empathy: Definition, enhancement, and relevance to the treatment of sexual abusers. Journal of Interpersonal Violence, 14(3), 257-284.

Rizzolatti, G., \& Craighero, L. (2004). The mirror neuron system. Annual Review of Neuroscience, 27, 169-192. 
Sale, E., Bellamy, N., Springer, J., \& Wang, M. (2008). Quality of provider-participant relationships and enhancement of adolescent social skills. The Journal of Primary Prevention, 29(3), 263-278.

Segal, E. A. (2006). Welfare as we should know it: Social empathy and welfare reform. In K. M. Kilty \& E. A. Segal (Eds.), The promise of welfare reform: Political rhetoric and the reality of poverty in the twenty-first century (pp. 265-274). Binghamton, NY: Haworth Press

Segal, E. A. (2007a). Social empathy: A new paradigm to address poverty. Journal of Poverty: Innovations on Social, Political \& Economic Inequalities, 11(3), 65-81.

Segal, E. A. (2007b). Social empathy: A tool to address the contradiction of working but still poor. Families in Society: The Journal of Contemporary Social Sciences, 88(3), 333-337.

Segal, E. A. (2008). Welfare reform: The need for social empathy. In I. Colby (Ed.), Comprehensive handbook of social work and social welfare, volume 4: Social policy and social practice (pp. 371-384). Hoboken, NJ: John Wiley \& Sons.

Tichener, E. (1909). Elementary psychology of the thought processes. New York: Macmillan.

Waldinger, R. J., Schultz, M. S., Hauser, S. T., Allen, J. P., \& Crowell, J. A. (2004). Reading others' emotions: The role of intuitive judges in predicting marital satisfaction, quality, and stability. Journal of Family Psychology, 18, 58-71.

\section{Author's note:}

Address correspondence to: Karen E. Gerdes, Ph.D., School of Social Work, Arizona State University, 411 North Central Ave, Suite 800, Phoenix, AZ 85004-0689. Email: kegerdes@asu.edu. 